\title{
Assessing dune erosion: 1D or 2DH? The Noorderstrand case study
}

\author{
P.F.C. van Geer $^{1}$ and M. Boers ${ }^{1}$ \\ ${ }^{1}$ Deltares, P.O.Box 177, 2600 MH, Delft, the Netherlands, Pieter.vanGeer@deltares.nl
}

\begin{abstract}
The Dutch safety assessment rules primarily focus on the cross-shore processes related to dune erosion during an extreme storm. A case study of the Noorderstrand (Schouwen) reminds us of the importance of taking into account effects of these alongshore processes. Both a study of the available (GIS) data and an extensive study with the numerical model XBeach show various processes that influence the amount of dune erosion during an extreme storm. Long-term processes that lead to migration of sand waves on the beach as well as the edge of the nearby channel building out seaward are present in both the measurement data and the model simulations. The resulting variation in the beach geometry causes a strong redistribution of sediment in alongshore direction during an extreme storm, leading to a sediment balance difference up to $100 \mathrm{~m}^{3} / \mathrm{m}$ measured along a cross-shore transect. Redistribution of the sediment alongshore proves not only to be dependent on the beach geometry, but also on the wind direction during the storm.
\end{abstract}

\section{INTRODUCTION}

Each primary sea defense in The Netherlands needs to be assessed for safety on a regular basis. Currently, the assessment rules for dune erosion prescribe a 1D model Duros + to calculate dune erosion, despite the fact that it is outside the range of validity for some locations. Recently, during the second assessment round, a dune section at the Noorderstrand did not pass the assessment. During the search for a solution to this safety problem, also 2D simulations were performed to assess dune erosion in this area. These simulations reminded us once again of the importance of taking into account alongshore processes when looking at dune erosion. This paper describes and discusses several findings obtained from these simulations.

The Noorderstrand lies right South of the Brouwensdam (Figure 1). Before this dam was built, a relatively deep channel positioned itself close to the shoreline. After closing off the Grevelingen, this channel remained near the coastline and started filling up. The channel is still present, but the rate sediment is deposited in the former tidal channel is rapidly decreasing nowadays. Furthermore, there is only one dune row. At one particular location, the dune is relatively narrow, causing the dune section not to reach the required level of safety.

\section{APPROACH}

To investigate dune erosion as a 2D process we used an XBeach model [Roelvink et al. 2009] that we setup for the area of the Noorderstrand. XBeach is a two-dimensional, numerical, wave group resolving, morphological model that supports slumping of dune faces. It can therefore calculate hydrodynamics and dune erosion for an area like the Noorderstrand. Since we do not have data that quantifies the impact of a storm in that area, it is hard to calibrate the model quantitatively. There are, however, many measurements of the bathymetry of that area, which allows us to qualitatively verify the model by matching observed long-term developments with processes that occur during a simulated storm. This paper shows that several of the physical processes that occur during an XBeach simulation support the long-term development we retrieved from the measurement data. Having confidence in the model outcome in a qualitative sense, we can now look at the qualitative effect of assessing dune erosion as a $2 \mathrm{D}$ process instead of a $1 \mathrm{D}$ process only.

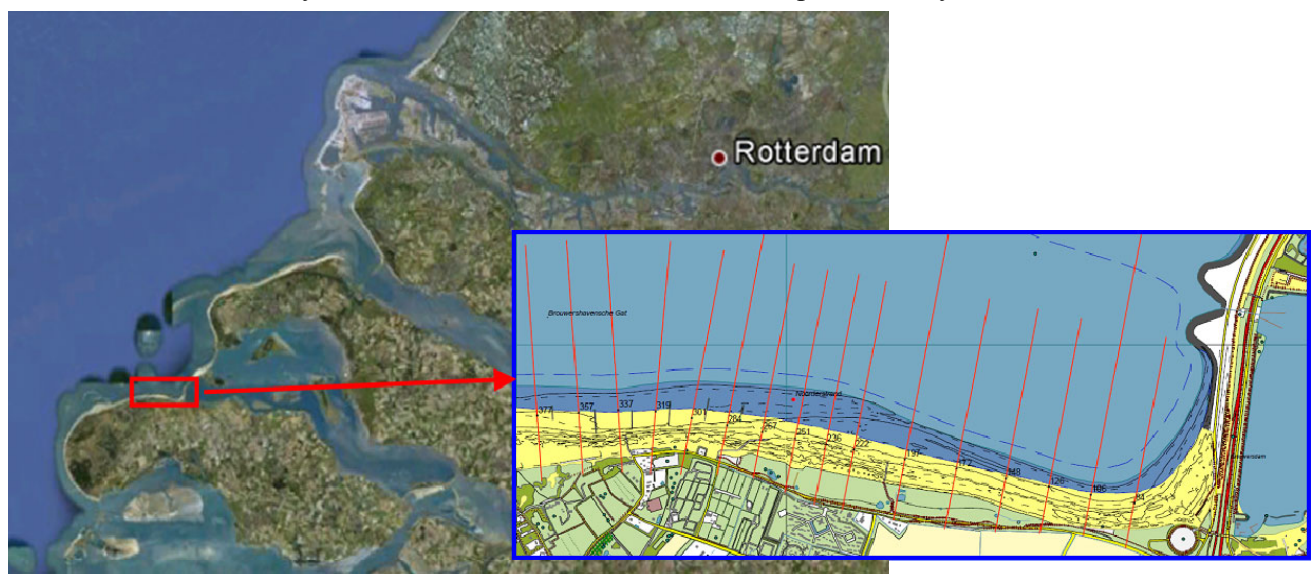

Figure 1: Overview of the location and orientation of the Noorderstrand area. 

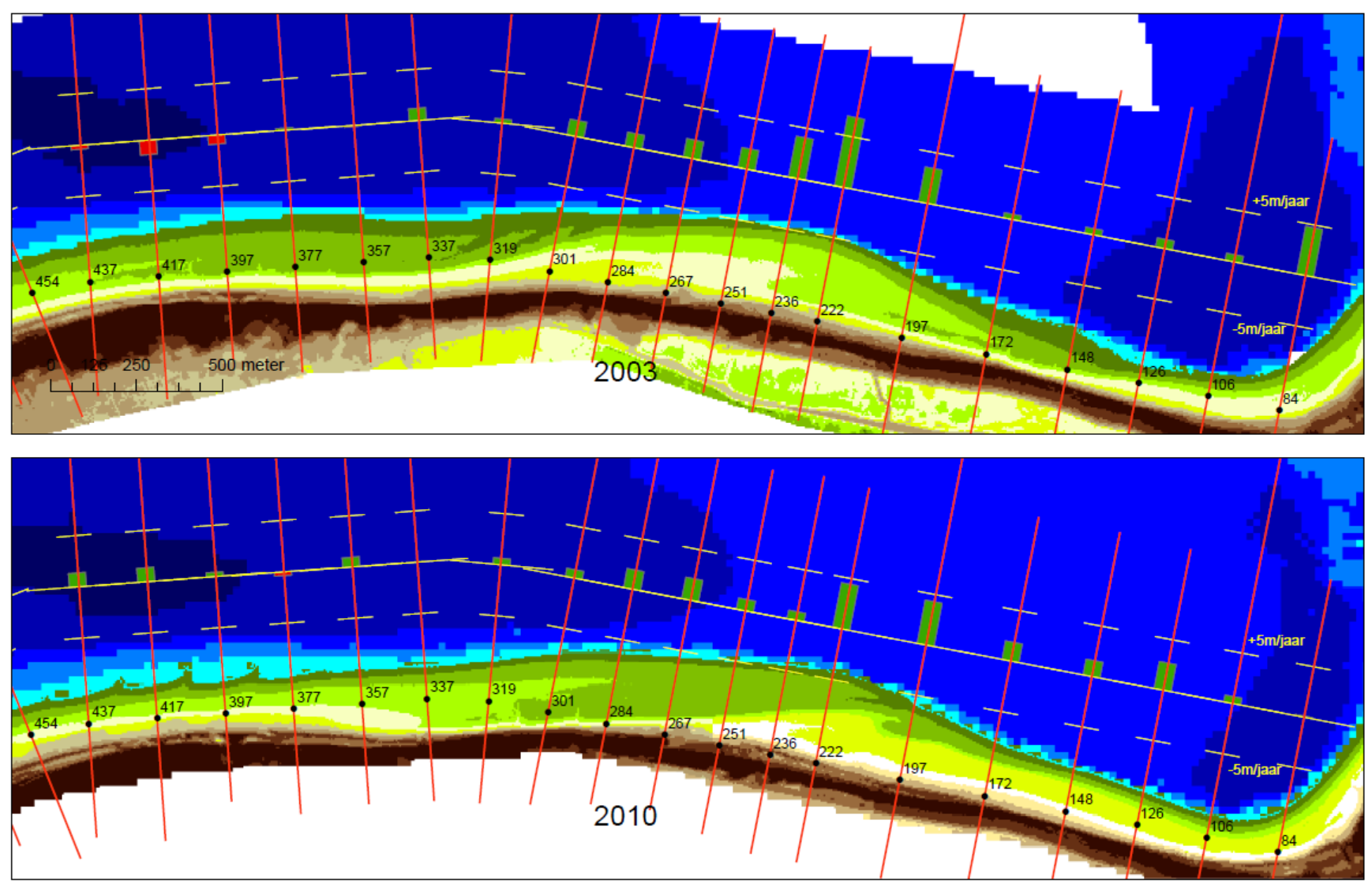

Figure 2: Development of the beach and channel near the Noorderstrand. The light green areas show a sand wave moving eastward and a new one entering at the western side of the area. The green bars denote the seaward movement rate of the edge of the channel.
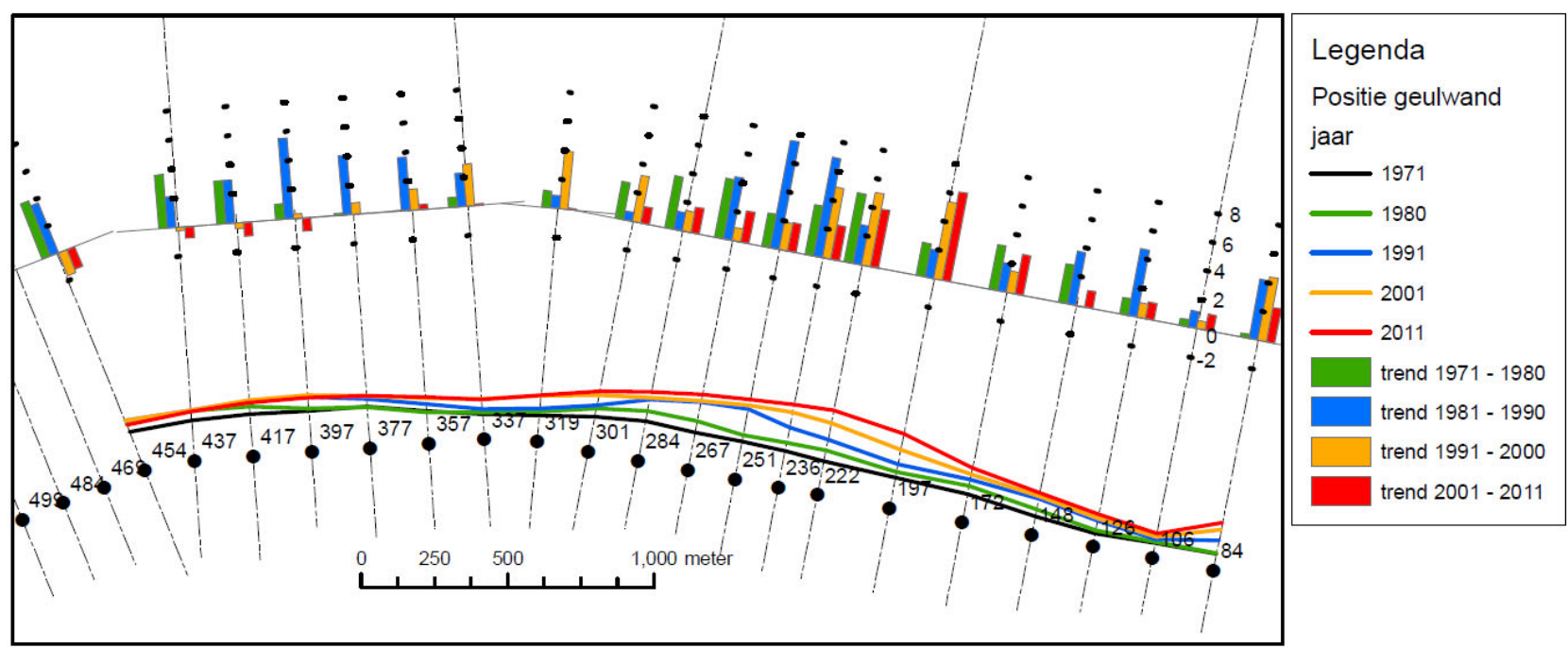

Figure 3: Development of the edge of the channel in time. The lines show the averaged position of the slice between $-3 m+N A P$ and $-5 m+$ $N A P$ for a specific year. The bars denote the movement of that line at a particular location (in m/year). 


\section{MORPHOLOGICAL DEVELOPMENT NOORDERSTRAND}

Measurements of the bathymetry near the Noorderstand have been carried out on a yearly basis. From these measurements, several trends can be identified. From the moment of finishing the Brouwersdam, the channel, for example, started filling up. This process slowed down in the past 10 years. Two trends draw our attention with respect to verifying XBeach calculation.

First, there appears to be a so-called sand wave on the upper (dry) part of the beach. Between $3 \mathrm{~m}+\mathrm{NAP}$ and $1.5 \mathrm{~m}+\mathrm{NAP}$ sand waves travel from West to East. Figure 2 shows the measured bathymetry of 2003 in comparison with the bathymetry of 2010 . The dry part of the beach (yellow and light green colors) shows a bulk of sand moving from transect 251 eastward to 222 / 197. A new wave is starting to develop near transect 357 . The magnitude of the bulks of sand traveling along the coast increased after the nourishments of 1994 and 1995 and slightly decreased again due to another nourishment in 2000.

The second trend is related to the movement of the edge of the channel near the Noorderstrand. Figure 3 shows the averaged position of the channel in time. This line tends to gradually build out seaward (and to the east) between transect 267 and 197.
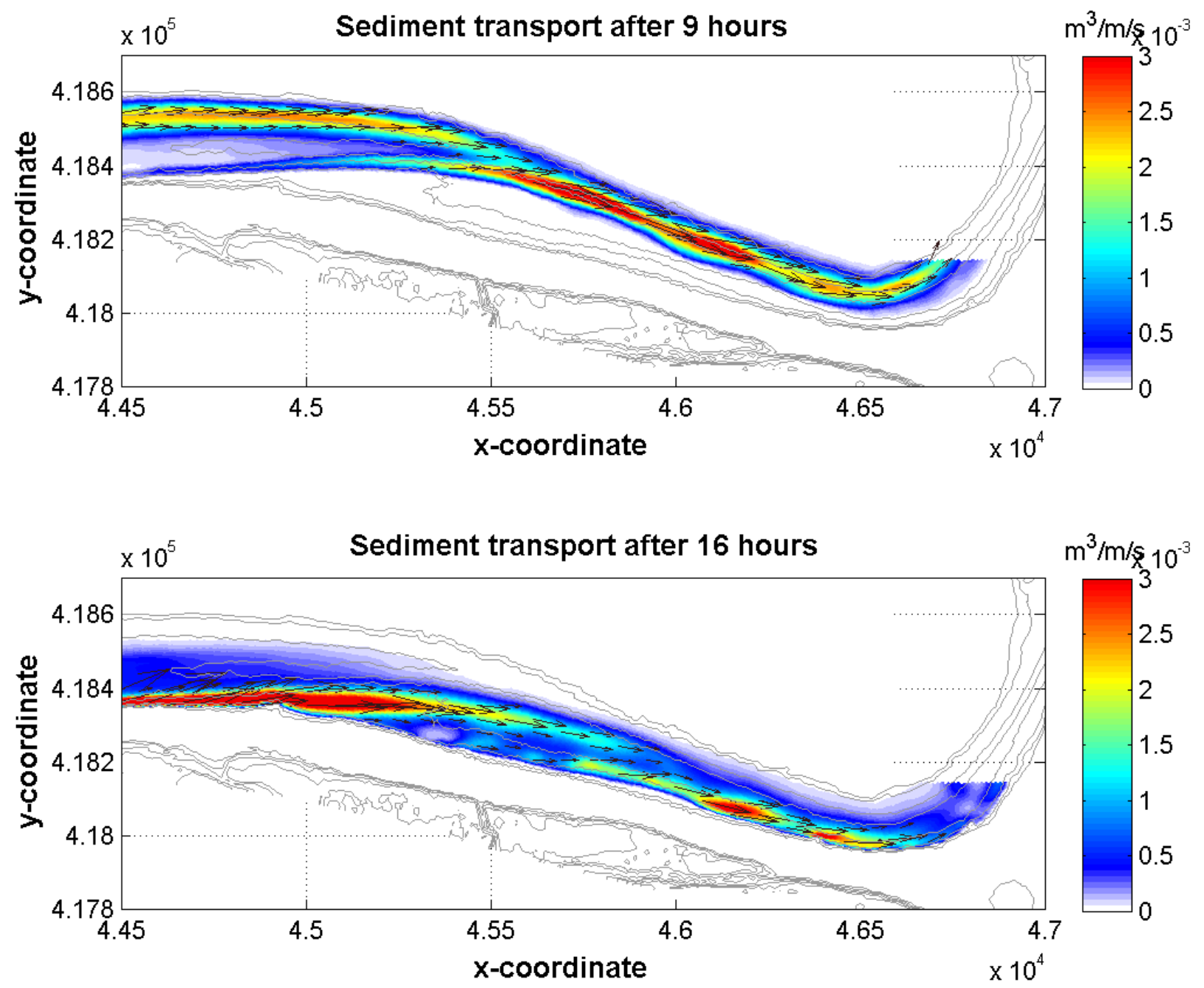

Figure 4: Sediment transport direction and magnitude near the Noorderstrand at two stages during a once in 10 years storm as calculated by XBeach. 

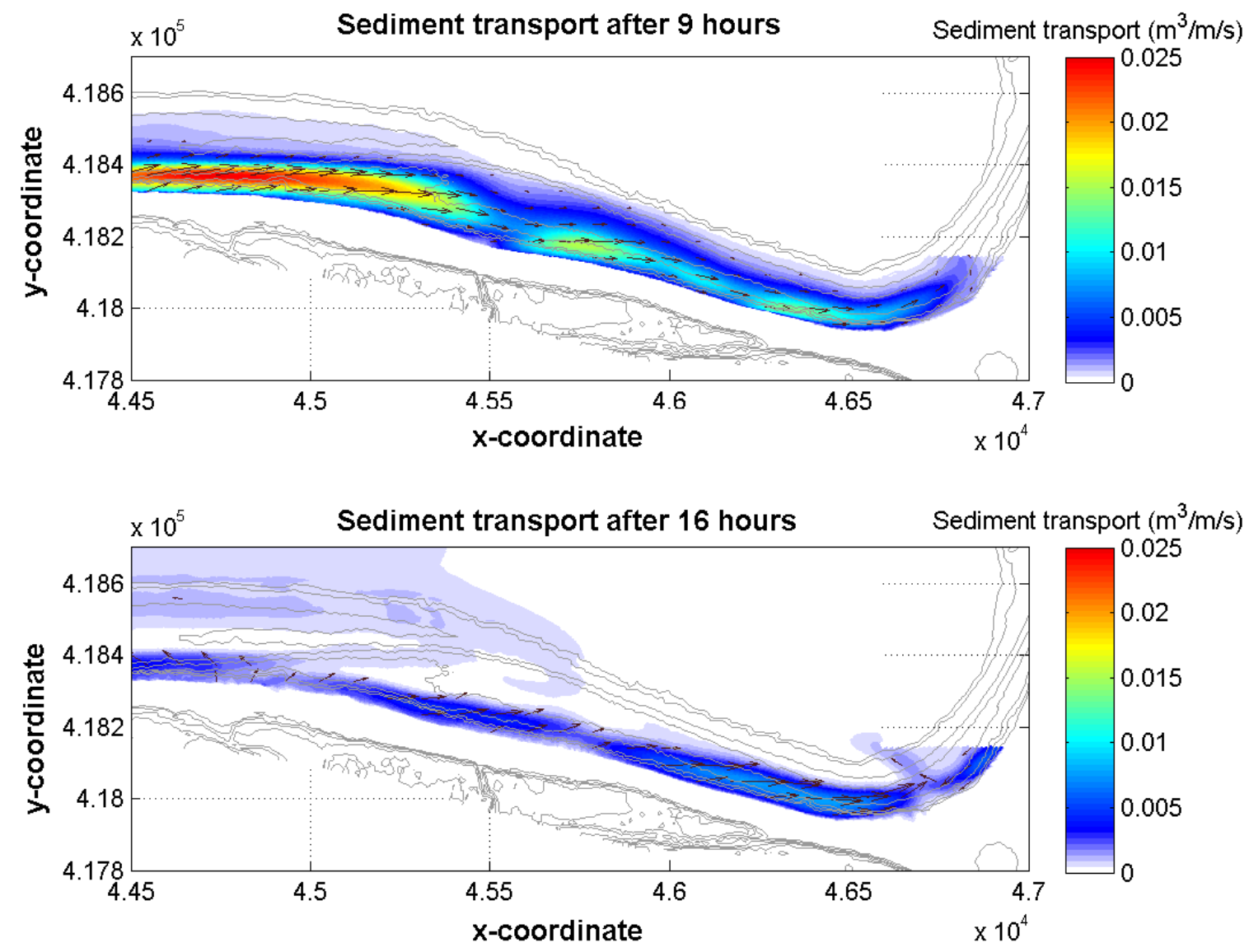

Figure 5: Sediment transport direction and magnitude near the Noorderstrand during a storm from north west and a northern storm.

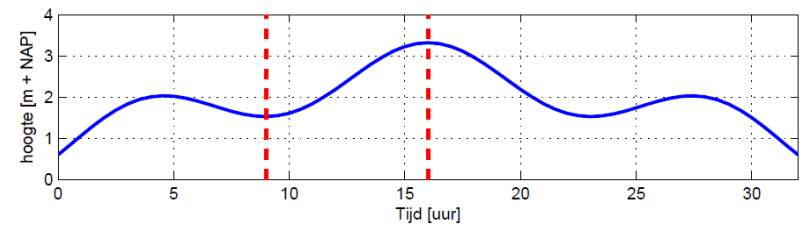

Figure 6: Applied storm surge for a once in 10 years storm.

\section{VERIFICATION OF XBEACH}

On the XBeach model, we imposed a storm surge and wave boundary conditions that varied in time. Figure 6 visualizes the used storm surge, which corresponds with a storm with a probability of occurrence of once in 10 years. We used a similar surge to simulate an extreme storm that matches the conditions that we use to assess the safety of the dunes at the Noorderstrand.

The lack of measurement data before and after storm events makes it impossible to calibrate any dune erosion model for the Noorderstrand area. While analyzing the results of the uncalibrated model, we did however identify processes in our simulations that support the observed long-term development of the bathymetry.
Figure 4 shows calculated sediment transport patterns after 9 and 16 hours of storm (also indicated by red dashed lines in Figure 6). After 9 hours of storm (when the water levels are still relatively low) sediment transport mainly occurs right at the edge of the channel, causing sediment to drop over the edge into the channel. Mostly between transect 236 and 197. This process supports a seaward displacement of the edge of the channel.

The calculating sediment transport at the peak of the storm (after 16 hours) mainly occurs higher on the beach and initiates movement of the sediment from East to West. Also this process supports the measured long-term bathymetrical changes.

\section{MORPHODYNAMICS DURING AN EXTREME STORM}

When assessing dune erosion with a 1D model, sediment that erodes from the dune face is assumed to settle on the beach further offshore, without interacting with neighboring transects. This assumption does not necessarily have to be valid for any location.

In case of the Noorderstrand, oblique wind and waves force an alongshore current that varies in direction and magnitude as shown in Figure 4. This causes sediment transport not just in cross-shore direction, but also along the coastline. Gradients in 
this longshore sediment transport cause not all cross-shore transects to have a balance between the amount of eroded sediment and the amount of accreted sediment. Eroded sediment in the western part of the area travels eastwards and contributes to the accretion in another transect.

\section{Alongshore redistribution of sediment}

Figure 7 shows the difference between accretion and erosion along transects from west to east in the study area, interpolated from the model bathymetry at the end of the simulation with a northwestern wind. The figure shows that the difference between the amount of eroded sediment and the amount of accreted sediment in the calculation can reach $100 \mathrm{~m}^{3} / \mathrm{m}$. At some locations, this doubles the amount of eroded sediment above storm surge level.

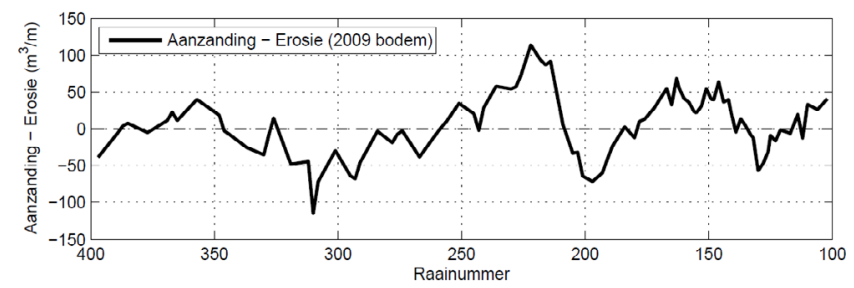

Figure 7: Accretion - erosion along the coastline of the Noorderstrand as calculated by XBeach with an extreme storm from $N W$.

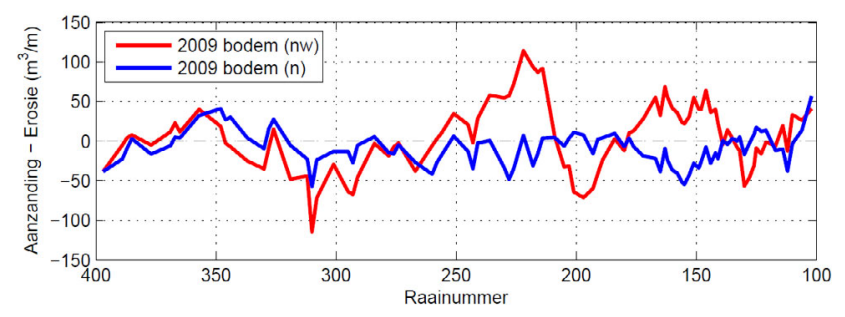

Figure 8: Accretion - Erosion along the coastline as calculated by XBeach. The red line shows the sediment balance after calculation with a northwestern storm. The blue line shows the sediment balance along the coastline after calculating a northern storm.

\section{Sensitivity of disturbed sediment balance}

The redistribution of sediment along the coast appears to be driven by the alongshore current gradients that exist during a northwestern storm. Calculations with varying wind direction, but similar characterization of the surge level in time, revealed that the redistribution of sediment in alongshore direction changes dramatically with changing wind direction. Figure 5 compares sediment transport during a northwestern storm with sediment transport calculated for a northern storm. Due to the change if the angle of incident of the waves, the northern storm primarily causes sediment to travel cross-shore (as assumed in a 1D model), whereas the northeastern storm mainly induced sediment transport in the alongshore direction. This change of the sediment transport processes and corresponding gradients also have an effect on the redistribution of sediment in the alongshore direction. Figure 8 (red line) shows the same redistribution during a northwestern storm as displayed in Figure 7. The blue line shows that redistribution of sediment during the northern storm reached just around $40 \mathrm{~m}^{3} / \mathrm{m}$.

\section{DISCUSSION}

The case study of the Noorderstrand shows that 2D processes can have a significant influence on the calculated amount of dune erosion. Especially while assessing dune safety at locations with a complex foreshore, such as the Noorderstrand, one should be cautious with applying a 1D model only. Redistribution of sediment in the alongshore direction can have an important effect on the height of the beach in neighboring transects and therefore also the amount of eroded sediment.

The Dutch assessment rules for dune safety [TRDA2006, 2007] prescribe the assessment of dune erosion during an extreme storm with the help of the 1D Duros+ model. Although the assessment rules do indicate that the remaining (boundary) profile after a storm should be continuous along the coastline to prevent flooding, alongshore processes are not taken into account while assessing the amount of erosion during an extreme storm event. The rules do not encourage assessors to judge the importance of alongshore processes. The Noorderstrand case study showed a contribution of redistribution of sediment can influence the amount of eroded sediment significantly and should be something to look after when assessing dune safety in areas with a complex foreshore.

Due to the absence of a proper calibration of the model, results presented in this study can only be interpreted qualitatively. Any definite conclusions regarding the safety of the Noorderstrand area would be one step ahead of reality.

\section{ACKNOWLEDGEMENT}

Waterschap Scheldestromen is kindly acknowledged for commissioning Deltares to carry out this study. Next to that we would like to thank dhr. ir. Hans van de Sande (Waterschap Scheldestromen) for his valuable input, that helped us reaching the results presented in this paper.

\section{REFERENCES}

Dano Roelvink, Ad Reniers, Ap van Dongeren, Jaap van Thiel de Vries, Robert McCall, Jamie Lescinski (2009), Modelling storm impacts on beaches, dunes and barrier islands, Coastal Engineering, 56(11-12),1133-1152, ISSN:0378-3839, 10.1016/j.coastaleng.2009.08.006.

TRDA2006 (2007), Technisch rapport duinafslag, experisenetwerk waterveiligheid 